\title{
The effects of Michelia alba oil against mould on brown rice and assessing the brain response using electroencephalogram (EEG)
}

\author{
Sumethee Songsamoe $^{1,3} \cdot$ Phanit Koomhin $^{2,3} \cdot$ Narumol Matan $^{1,3}$ (D)
}

Revised: 11 July 2020/Accepted: 31 July 2020/Published online: 6 August 2020

(C) Association of Food Scientists \& Technologists (India) 2020

\begin{abstract}
The objective of this study was to develop antifungal fragrant brown rice using the vapour phase of Michelia alba oil and to understand the effects of fragrant brown rice on consumer reactions using an electroencephalography (EEG) technique. The effect of $M$. alba oil vapour $(300-900 \mu \mathrm{L} / \mathrm{L})$ on the growth of moulds was studied in brown rice. Then, optimisation of the M. alba oil vapour $(300-900 \mu \mathrm{L} / \mathrm{L})$ was studied through sensory evaluation. Next, EEG was used to investigate the effect of fragrant cooked brown rice on human brain activity. In addition, the key components of $M$. alba oil on the sensory effects were determined. The results indicated that $M$. alba oil vapour $\geq 450 \mu \mathrm{L} / \mathrm{L}$ provided effective antifungal activity against natural moulds on brown rice for at least 90 days of storage at $25^{\circ} \mathrm{C}$ at $100 \% \mathrm{RH}$. Furthermore, the optimal concentration of $M$. alba oil vapour for enhancing consumer preference and acceptance of cooked brown rice was $300-600 \mu \mathrm{L} / \mathrm{L}$ with a rejection threshold of $2,052 \mu \mathrm{L} /$ L. Moreover, it was found that linalool was the main key component and caryophyllene and $\beta$-elemene were the minor components affecting the sensory quality enhancement. Interestingly, the EEG results showed that fragrant cooked brown rice could increase the power of alpha and beta waves in the human brain, indicating anti-stress effects
\end{abstract}

Narumol Matan

nnarumol@wu.ac.th; nnarumol@yahoo.com

1 Food Science and Technology, School of Agricultural Technology, Walailak University, Nakhon Si Thammarat 80160, Thailand

2 School of Medicine, Walailak University, Nakhon Si Thammarat 80160, Thailand

3 Research Center of Excellence in Innovation of Essential Oil, Walailak University, Nakhon Si Thammarat 80160, Thailand and a relaxed mood. Therefore, M. alba oil vapour demonstrated good potential to enhance consumer acceptance and preference for cooked brown rice while controlling the significant growth of moulds in brown rice.

Keywords Antifungal - Fragrant brown rice - Michelia alba oil vapour $\cdot$ Sensory $\cdot$ Electroencephalography

\section{Introduction}

Brown rice not only contains high nutritional values such as high protein, fibre, vitamins and mineral contents (Kalpanadevi et al. 2018) but also contains salutary health components, namely, tocopherol, phytosterol, $\gamma$-oryzanol, and $\gamma$-aminobutyric acid as well as phenolics and anthocyanins (Sapna et al. 2019). However, brown rice and its products are responsive to postharvest diseases caused by various moulds, especially, Aspergillus spp. A. flavus are a major cause of postharvest losses and diseases in brown rice and its products with a high frequency worldwide (Suhem et al. 2015). Recently, has been discovered that the application of essential oils such as that of Litsea cubeba (Suhem et al. 2015), bergamot (Songsamoe et al. 2016) and Michelia alba (Songsamoe et al. 2017) can suppress the growth of A. flavus in brown rice.

The new era of COVID-19 pandemic gives insights into the need for bioactive ingredients from food and herbs which could be used to increase the human immune system against infections (Galanakis 2020). The oil of Michelia alba contains aromatic constituents that exhibit various bioactivities. For example, it can be used as an anti-inflammatory agent to treat cramps, abdominal pain (Lee et al. 2005), fever, syphilis and malaria (Asaruddin et al. 2003), and It can also be used to protect against the growth 
of A. niger, A. flavus, Penicillium sp., Rhizopus sp., Fusarium sp., and Cladosporium sp. (Songsamoe et al. 2017). In addition, it has also been reported that the oil of $M$. alba has long been used in healthy food recipes because of its pleasant flavour and because its name sounds like a flower (Rout et al. 2006). Therefore, essential oil could be used as a functional additive in food products and in the development of new products with higher market value (Galanakis 2012). In order to avoid negative sensory effects and reduce the cost of using essential oil on a large scale, the use of M. alba oil in the vapour phase. Flavour and taste impact as well as consumer acceptance should be addressed in order to take the emerging technologies.

In consumer and sensory research of food products, consumers' physiological and emotional responses are emphasised because they are fully correlated with consumer product acceptability. Flavour and taste impact, as well as consumer acceptance should be addressed so as to utilize the emerging technologies (Galanakis 2013). Therefore, good understanding of consumers' physiological and emotional responses to food products is essential for success in food product design and food services (Desmet and Hekkert 2009). The samples and test situations could elicit positive or negative emotions which may generate different emotions to overall product performance (Worch et al. 2020). Many traditional explicit measurements, namely, preference, acceptance, liking and hedonic valuation, have been used for the evaluation of consumers' feelings and preferences (King and Meiselman 2010). Nowadays, brain activity, facial expression and heart rate could be used to study a physiological response of consumers (Lagast et al. 2017). To understand of consumers' emotional responses, non-verbal methods could be done such as look at food and smelling for cognitive by consumers (Kaneda et al. 2004). The measurement of brain activity by electroencephalography (EEG) is one interesting technique that has recently been applied in the consumer and sensory research of food products. It can provide useful and detailed data to support the understanding of consumer responses to food (Lagast et al. 2017). EEG data obtained from consumers after eating food have been considered in terms of brain function and consumers' emotional responses. A change in the spectral power of EEG waveforms can be interpreted as the feelings or brain functions of the consumer after consuming food. In addition, the asymmetry of EEG power from the right and left hemispheres of the brain can be interpreted as motivational tendency or food acceptability. Therefore, the objective of this work was to study the effect of $M$. alba oil on mould growth and to find a suitable volume of $M$. alba oil for application in brown rice to promote a positive reception from the consumer.

\section{Materials and methods}

\section{Essential oil}

M. alba oil extracted by steam distillation was obtained from Thai China Flavours and Fragrances Co., Ltd. of Thailand. The components of $M$. alba oil were determined using gas chromatography-mass spectrometry analysis. This analysis was carried out on a gas chromatographtandem mass spectrometer model 7890 B GC-700D MS from Agilent, USA, equipped with an Agilent HP-5 ms Ultra Inert column $(30 \mathrm{~m} \times 250 \mu \mathrm{m} \times 0.25 \mu \mathrm{m})$. The average helium carrier gas flow rate was $1 \mathrm{~mL} \mathrm{~min}^{-1}$, the injected volume was $1 \mu \mathrm{L}$, the split ratio of the column was 10:1, and the injector temperature was set at $250^{\circ} \mathrm{C}$. The initial column oven temperature was set at $40{ }^{\circ} \mathrm{C}$, then increased to $180^{\circ} \mathrm{C}$ at a rate of $10{ }^{\circ} \mathrm{C} / \mathrm{min}$ and held for $1 \mathrm{~min}$ and then raised to $300{ }^{\circ} \mathrm{C}$ at a rate of $5{ }^{\circ} \mathrm{C} / \mathrm{min}$. The detector temperature was set at $300{ }^{\circ} \mathrm{C}$. The components of the oil were identified by comparison of their mass spectra fragmentation and computer matching using the Wiley 10 and NIST 14 libraries (Database/ChemStation data system).

\section{Effect of $M$. alba oil vapour against $A$. flavus on MEA and natural mould on brown rice}

\section{Culture}

Aspergillus flavus $\left(10^{6} \mathrm{CFU} / \mathrm{mL}\right)$ was isolated from brown rice and obtained from the Research Center of Excellence in Innovation of Essential Oil, Walailak University, Nakhon Si Thammarat, Thailand. A. flavus was inoculated onto malt extract agar (MEA) before incubation at $25^{\circ} \mathrm{C}$ for 7 days. The spore suspension was prepared by pouring $9 \mathrm{~mL}$ of sterile water onto the agar slant and mixing. The number of viable spores was counted on the MEA.

\section{Antifungal activity testing on MEA}

The antifungal activity of $M$. alba oil vapour (extracted from the flowering part of the plant) was observed. For this, A. flavus (diameter $\sim 5 \mathrm{~mm}$ ) was added onto the centre of the MEA plate. M. alba oil of different volumes (150$900 \mu \mathrm{L})$ was added into the container $(1 \mathrm{~L})$. Then, the plate (without a lid) was placed inside the container. All containers were incubated at $25{ }^{\circ} \mathrm{C}$ for 5 days. The control sample was treated in the same way, but without the essential oil. After incubation, the colony diameter $(\mathrm{mm})$ of A. flavus on each plate was checked. The percent inhibition of mould growth was computed based on the following Eq. 1: 
Growth inhibition $(\%)=\frac{(\text { Control }- \text { Treatment }) \times 100}{\text { Control }}$

where Control $=$ the colony diameter $(\mathrm{mm})$ of A. flavus on the control plate; Treatment $=$ the colony diameter $(\mathrm{mm})$ of A. flavus on the sample plate.

\section{Brown rice grain storage with M. alba oil vapour}

The effect of $M$. alba oil vapour (0 (control), 300, 450, 600, 750 and $900 \mu \mathrm{L} / \mathrm{L}$ ) against natural mould on brown rice grains (100 g) was examined in a polyethylene (PE) plastic bag (available volume $=250 \mathrm{~mL}$, thickness $=220 \mu \mathrm{m}$ ). The bag was stored at $25{ }^{\circ} \mathrm{C}$ and $100 \% \mathrm{RH}$ for 90 days. During storage, the mould growth on the brown rice surface was observed, and the inhibitory period (day) was reported.

\section{Sensory assessment of $M$. alba oil vapour on cooked brown rice}

\section{Preference and acceptance testing}

Different volumes of $M$. alba oil vapour (300-900 $\mu \mathrm{L}$ ) were applied to brown rice $(400 \mathrm{~g})$ in a container $(1 \mathrm{~L})$. The container was closed and stored at $25^{\circ} \mathrm{C}$ for 30 days. Then, the brown rice $(150 \mathrm{~g})$ was soaked in a pot for $5 \mathrm{~min}$ with $400 \mathrm{~mL}$ of deionised water. Next, the rice was cooked in an automatic rice cooker (Otto Kingglass Co., Ltd. Thailand). After cooking, the brown rice samples were subjected to sensory analysis by an untrained panel (89 panellists) ranging in age from 20 to 45 years.

In order to find the preferred concentration of $M$. alba vapour in brown rice, five sessions of paired preference tests were conducted for each panellist. Each pair of samples consisted of a cooked brown rice control sample (without $M$. alba oil vapour, Sample A) and a stimulus sample (treated with $M$. alba oil vapour at concentrations of $300[\mathrm{~B}], 450[\mathrm{C}], 600[\mathrm{D}], 750[\mathrm{E}]$ and $900 \mu \mathrm{L}[\mathrm{F}])$. Panellists were asked to taste the samples in each pair (A$\mathrm{B}, \mathrm{A}-\mathrm{C}, \mathrm{A}-\mathrm{D}, \mathrm{A}-\mathrm{E}$ and $\mathrm{A}-\mathrm{F}$ at random) and to indicate their preference (Lima Filho et al. 2015). In each test, after the panellists rinse their mouths with water, they received a new pair of samples every $5 \mathrm{~min}$. The preferred concentration of essential oil in cooked brown rice compared with the control was analysed using the chi-squared $\left(\chi^{2}\right)$ $(p=0.05)$.

In addition, a nine-point hedonic scale $(9=$ extremely like, $1=$ extremely dislike) was used to determine the degree of acceptance of the specimens in terms of odour, flavour (a combination sensation perceived by the oral and nasal cavities), taste (the sensation perceived by the tongue) and overall liking (Meilgaard et al. 1999).

\section{Rejection threshold}

The rejection threshold (RT) was also determined. A graph was constructed of the average hedonic value (Y-axis) as a function of the $M$. alba oil vapour concentration in the brown rice sample under investigation (X-axis). The cutoff point of the $\mathrm{Y}$-axis was denoted on the graph by a dashed line identifying the hedonic score of 5 (the hedonic term "indifferent"), demonstrating the transition point between sensory acceptance and rejection of the cooked brown rice. The "indifferent" term of the hedonic scale was considered a rejection point since a consumer indifferent to a product is not likely to buy it (Della Lucia et al. 2014). To determine the $M$. alba oil vapour concentration at which sensory rejection of the cooked brown rice begins to occur, a regression model was adjusted to the points of the Y-axis. To select the model that was the best fit of the data, the significance of the regression coefficients and the coefficient of determination $\mathrm{R}^{2}$ was evaluated using Statistica software (StatSoft, USA).

\section{Determination of a key component of M. alba oil vapour in sensory effects}

The components of M. alba oil vapour absorbed into brown rice grains and remaining in cooked brown rice were investigated using GC-MS analysis. Each sample (10 g) was extracted with ethyl acetate $(10 \mathrm{~mL})$. Then, it was mixed gently by shaking overnight. Next, it was filtered and centrifuged at 12,000 rpm for $5 \mathrm{~min}$. Afterward, the supernatant was reduced to dryness under a stream of nitrogen at room temperature. Finally, the residue of each sample was dissolved in $1 \mathrm{~mL}$ ethyl acetate before $1 \mathrm{~mL}$ aliquots of each solution were subjected to GC-MS analysis under the same conditions used in the previous section.

In addition, the components of $M$. alba oil vapour which had the main effects in enhancing the sensory qualities of cook brown rice were determined using sensory analysis. Differences from the control were used to investigate matches between the odour of treated cooked brown rice and the odours of components of $M$. alba oil. The control (cooked brown rice treated with $M$. alba oil vapour at $600 \mu \mathrm{L} / \mathrm{L}$ ) was prepared by the same procedure used in the previous section. The pure components of $M$. alba oil (linalool, $\beta$-elemene and caryophyllene) were prepared in a smelling box. Afterward, the specimens were subjected to sensory analysis by an untrained panel (50 panellists, 35 females and 15 males) ranging from 18 to 47 years of age. The specimens were presented to panellists seated separately in control booths. A 10-point scale of difference 
from the control ranging from "not different" to "extremely different" was used to determine the degree of difference from the control of the specimens in terms of odour.

\section{Physical and chemical properties of brown rice after treatment with $M$. alba oil vapour}

Brown rice treated with $M$. alba oil vapour at $600 \mu \mathrm{L} / \mathrm{L}$ at $25{ }^{\circ} \mathrm{C}$ for 30 days and the control (without essential oil) evaluated for physical and chemical properties. In brief, optimal cooking time was determined using the glass platewhite center method. The colour of cooked brown rice was determined by a colorimeter (ColorFlex, Hunter Associates Laboratory, USA). The texture profile analysis (TPA) of brown rice was tested using a texture analyzer (LR 5K MK4, Lloyd Instrument Co., Ltd., England). A cylinder probe of 45 diameters was used to compress the sample to $75 \%$ deformation at the test speed of $5 \mathrm{~mm} / \mathrm{s}$. The chemical compositions of brown rice were determined by the standard methods of AOAC (2019).

\section{Effect of cooked brown rice containing M. alba oil vapour on human brain activity}

\section{Participants}

Ten healthy volunteers (male $=5$, female $=5$ ) between the ages of 20 and 31 were recruited from the staff and students at Walailak University. They were determined as healthy by a medical questionnaire. The testing protocol was approved by the Human Research Ethics Committee of Walailak University (Protocol Number WUEC-16-115-01).

\section{Cooked brown rice samples}

Brown rice specimens were treated with $M$. alba oil vapour at $600 \mu \mathrm{L} / \mathrm{L}$ at $25{ }^{\circ} \mathrm{C}$ for 30 days. After cooking in an automatic rice cooker, the brown rice specimens were used to test olfactory responses by the EEG technique.

\section{EEG procedure}

The effect of cooked brown rice containing M. alba oil vapour on human brain activity was investigated using electroencephalography (EEG) (Research Institute for Health Science, Health Sciences Research Center Building, Walailak University, Nakhon Si Thammarat, Thailand). The internationally standardised 10-20 system (FP1, FP2, F7, F3, FZ, F4, F8, T7, C3, CZ, C4, T8, M1, M2, P7, P3, $\mathrm{PZ}, \mathrm{P} 4, \mathrm{P} 8, \mathrm{O} 1, \mathrm{O} 2)$ was employed to record the spontaneous EEGs obtained from participants during smelling and mouthing and after swallowing of cooked brown rice.
Power spectral analysis was performed using Curry 7 (Compumedics, Australia), and results were compared between rice with and without $M$. alba oil vapour.

The testing sessions began at 10:00 a.m. Participants were instructed to refrain from alcohol consumption for $12 \mathrm{~h}$ (overnight), to sleep more than $8 \mathrm{~h}$ prior to the test sessions and to arrive at the EEG laboratory at 8:30 a.m. Participants were then informed that they should not drink or eat until the test session began at 10:00 a.m. The test conditions and procedures were explained to the participants prior to completion of the questionnaire. Then, the participants' heart rates, temperatures, weights and heights were recorded. Next, electrodes were placed on the scalp of participants while they were seated in a recliner with minimal movement. The EEG recording was carried out following the procedure shown in Fig. 1. The baseline EEG was recorded while the participants closed their eyes for 2 min. Then, EEGs were recorded during smelling, mouthing, and swallowing and after swallowing $(5 \mathrm{~min})$ the cooked brown rice samples. Each step took place in 2-min intervals. After all the steps were completed, the electrode cap was removed.

\section{Statistical analysis}

All results were expressed as the mean \pm standard deviation. One-way ANOVA and Duncan's post hoc test, with $p<0.05$ being considered statistically significant, were employed. Kruskal-Wallis and Wilcoxon matched-pairs signed rank tests were used with non-parametric data. Statistical analysis was performed using Statistica software (StatSoft, USA).

\section{Results and discussion}

\section{Effect of M. alba oil vapour on mould growth}

The effects of $M$. alba oil in the vapour phase on the growth of A. flavus on MEA found that the vapour phase of M. alba oil at a concentration of $450 \mu \mathrm{l} / \mathrm{L}$ could inhibit the growth of A. flavus on MEA (by 100\%), followed by vapour at concentrations of $\geq 150-400 \mu \mathrm{l} / \mathrm{L}$ (by $>90 \%$ ). These findings demonstrated that $M$. alba oil vapour possessed good antifungal activity. In addition, the results from the sensory test demonstrated that the appropriate volume of M. alba oil vapour was $300-600 \mu \mathrm{l} / \mathrm{L}$ in cooked brown rice, which showed the like slightly to like moderately in the sensory test. Therefore, using $M$. alba oil vapour from 300 to $600 \mu \mathrm{l} / \mathrm{L}$ on brown rice showed positive effects on antifungal activity and consumer acceptance. In addition, the effects of $M$. alba oil in the vapour phase on the growth of natural mould on brown rice clearly 


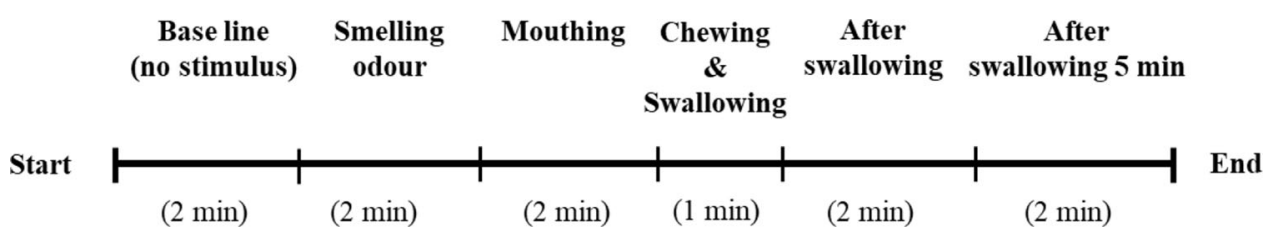

Fig. 1 EEG recording showing the procedure of the baseline, smelling, mouthing, after swallowing and 5 min after swallowing steps at 2-min intervals

showed that $M$. alba oil vapour $(\geq 450 \mu \mathrm{l} / \mathrm{L})$ on brown rice under accelerated storage conditions could prolong the shelf-life of brown rice by more than 6 times (90 days) compared with that of the control sample (15 days).

The results from this experiment confirmed that $M$. alba in the vapour phase $(\geq 450 \mu \mathrm{l} / \mathrm{L})$ could completely inhibit the growth of A. flavus. By performing a comparison with the $M$. alba oil from the leafy part of the plant, it was found that oil from the flowering part is less effective against $A$. flavus than that from the leafy part (Songsamoe et al. 2016). Linalool (the major component of $M$. alba oil), a monoterpene alcohol, is widely known as a highly effective antimicrobial compound (Suppakul et al. 2011). It can disrupt the cell walls and membranes of moulds (Zeng et al. 2011). The safety of linalool has been reported in a test using female mice given $375 \mathrm{mg} / \mathrm{kg}$ of linalool via a stomach tube for 5 days (Vollmuth et al. 1989). Currently, linalool has been approved by the US-FDA as a GRAS or food additive with no limitations (Hongratanaworakit and Buchbauer 2004). Therefore, using $M$. alba oil in the vapour phase could be safe.

\section{Effect of $M$. alba oil vapour on the sensory qualities of cooked brown rice}

The results of consumer acceptability of cooked brown rice treated with $M$. alba oil vapour in Table 1 show that brown rice treated with $M$. alba oil vapour at 300-900 $\mu \mathrm{L} / \mathrm{L}$ could increase the consumer acceptability of cooked brown rice. Concerning the effects of different concentrations of $M$. alba oil vapour, treating brown rice with $M$. alba oil vapour at low concentrations (300-600 $\mu \mathrm{L} / \mathrm{L})$ could significantly improve all sensory attributes of the cooked brown rice (odour, flavour, taste, colour and overall liking). Increasing the concentration of $M$. alba oil vapour to higher than $600 \mu \mathrm{L} / \mathrm{L}$ initially resulted in a decrease in the liking scores for taste, followed by flavour and overall liking, but the participants' liking scores were still higher than those for normal cooked brown rice (untreated with $M$. alba vapour). While there were lower effects from higher vapour concentrations on the liking scores of the odour of cooked brown rice, the liking scores were still high.

The rejection threshold (RT) is best predicted by the model Eq. 2. The coefficient of determination $\left(\mathrm{R}^{2}\right)$ was 0.75 , which indicated that the model equations adequately fit the data. The RT was determined as $2052 \mu \mathrm{L} / \mathrm{L}$, above which concentration the cooked brown rice will be rejected by consumers. Taken together, these findings indicated that treating brown rice grains with $M$. alba oil vapour at 300$600 \mu \mathrm{L} / \mathrm{L}$ was optimal for improving the sensory qualities of cooked brown rice.

$Y=-0.0011 X+7.2573$

where $\mathrm{Y}$ is the predicted hedonic score and $\mathrm{X}$ is the $M$. alba vapour concentration.

It is well known that the high volatility, reactivity, odour and flavour of essential oils might cause severe interference with food product sensory qualities, resulting in positive or negative characteristics (Espina et al. 2014; Kim et al. 2013). The strong flavour of many essential oils is primarily limiting when used in products at high concentrations when applied to food, while the appropriate matching of essential oil flavours to food products can provide higher acceptance at higher concentrations. For example, lemon
Table 1 The effect of cooked brown rice treated with $M$. alba oil vapour on consumer acceptance

\begin{tabular}{|c|c|c|c|c|}
\hline \multirow[t]{2}{*}{ Treatments } & \multicolumn{4}{|c|}{9 point hedonic scale } \\
\hline & Odour & Taste & Flavour & Overall \\
\hline M. alba flower oil $300 \mu \mathrm{L} / \mathrm{L}$ & $6.8 \pm 1.5^{\mathrm{a}}$ & $6.9 \pm 1.4^{\mathrm{a}}$ & $6.8 \pm 1.3^{\mathrm{a}}$ & $7.1 \pm 1.3^{\mathrm{a}}$ \\
\hline M. alba flower oil $450 \mu \mathrm{L} / \mathrm{L}$ & $6.6 \pm 1.4^{\mathrm{a}}$ & $6.5 \pm 1.6^{\mathrm{ab}}$ & $6.5 \pm 1.4^{\mathrm{ab}}$ & $6.7 \pm 1.5^{\mathrm{b}}$ \\
\hline M. alba flower oil $600 \mu \mathrm{L} / \mathrm{L}$ & $6.5 \pm 1.5^{\mathrm{a}}$ & $6.6 \pm 1.5^{\mathrm{ab}}$ & $6.5 \pm 1.6^{\mathrm{a}}$ & $6.9 \pm 1.4^{\mathrm{a}}$ \\
\hline M. alba flower oil $750 \mu \mathrm{L} / \mathrm{L}$ & $6.4 \pm 1.8^{\mathrm{a}}$ & $6.2 \pm 1.8^{\mathrm{b}}$ & $6.0 \pm 1.8^{\mathrm{bc}}$ & $6.3 \pm 1.7^{\mathrm{ab}}$ \\
\hline M. alba flower oil $900 \mu \mathrm{L} / \mathrm{L}$ & $6.3 \pm 1.7^{\mathrm{a}}$ & $6.1 \pm 1.8^{\mathrm{b}}$ & $6.0 \pm 1.9^{\mathrm{c}}$ & $6.3 \pm 1.7^{\mathrm{ab}}$ \\
\hline Control & $5.9 \pm 1.6^{\mathrm{b}}$ & $6.0 \pm 1.6^{\mathrm{b}}$ & $5.9 \pm 1.5^{\mathrm{c}}$ & $6.1 \pm 1.4^{\mathrm{c}}$ \\
\hline
\end{tabular}

${ }^{\mathrm{a}-\mathrm{c}}$ Different superscripts are significantly different $(p<0.05)$ 
oil was acceptable at higher concentrations than were other essential oils when applied in tomato juice, vegetable soup, or poultry burgers, because of the higher appreciation of its sour, citrus-like flavour (Espina et al. 2014). Therefore, food compatibility and the matching of essential oil components with the physicochemical characteristics of food products have a significant impact on essential oil applications concerning food product sensory qualities. In addition, avoiding using essential oils in the liquid phase could reduce the concentration and the effects on food properties (Tyagi et al. 2012). The results of this work illustrated that appropriate matching of the $M$. alba oil and cooked brown rice flavour by using a small volume of $M$. alba oil in the vapour phase could improve the sensory quality of the cooked brown rice in terms of odour, flavour, taste and colour and increase consumer preference and acceptance. Remarkably, this finding can apply to $M$. alba oil vapour in brown rice at a wide range of concentrations. This is because we can use $M$. alba oil vapour at concentrations up to approximately $1200 \mu \mathrm{L} / \mathrm{L}$ (predicted) without negative effects on sensory properties, and the concentration can be increased to $<2052 \mu \mathrm{L} / \mathrm{L}$ (RT) and remain within the consumer acceptance level.

\section{Determination of a key component of $M$. alba oil vapour in sensory effects}

The components identified in $M$. alba oil, brown rice grain samples and cooked brown rice samples are shown in Table 2. In $M$. alba oil, 67 components were identified, representing $99.62 \%$ of the total components. Linalool $(43.47 \%)$, $\beta$-elemene $(8.03 \%)$, caryophyllene $(6.80 \%)$, methyl 2-methylbutyrate $(4.05 \%)$ and $\beta$-selinene $(4.00 \%)$ were found to be major and minor components of $M$. alba oil. Only 24 components were found in brown rice grains after exposure to $M$. alba oil vapour. This illustrated that not all components of the $M$. alba oil vapour were absorbed into the brown rice grains. However, all major and minor components could be released from the absorbent material and were absorbed by brown rice grains in similar ratios to their presence in $M$. alba oil, since the vapour was present at a high ratio within the system, while other components with very low ratios could be not detected in the sample. After soaking and cooking the brown rice, some components were lost, and it was found that only 14 components remained in the cooked brown rice. The components with lower molecular weights and boiling points such as methyl 2-methylbutyrate $\quad\left(\mathrm{MW}=116.158 \mathrm{~g} \mathrm{~mol}^{-1}, \quad\right.$ boiling point $=116.00{ }^{\circ} \mathrm{C}$ ) were easier to lose due to heat more compared to the components with higher molecular weights and boiling points such as $\beta$-selinene $\left(\mathrm{MW}=204.357 \mathrm{~g} \mathrm{~mol}^{-1}, \quad\right.$ boiling point $\left.=263.00{ }^{\circ} \mathrm{C}\right)$. Noticeably, among the major and minor components, linalool was lost due to heat during cooking more than were $\beta$-elemene and caryophyllene, since it has a lower molecular weight and boiling point, which affected the ratio of components in the cooked brown rice ( $\beta$-elemene $=34.38 \%$, caryophyllene $=19.58 \%$ and linalool $=$ $11.32 \%)$. Hence, the MW and number of aromatic rings, hydroxyl, carboxylic and methylation groups constitute different solutes that were attracted into the target material (Galanakis 2015).

Although $\beta$-elemene was present at a higher ratio in cooked brown rice than were caryophyllene and linalool, it did not play the main role in terms of the odour improvement of cooked brown rice. The score of difference from the control in sensory analysis indicated that the odour of linalool resembled that of the control (cooked brown rice treated with $M$. alba oil vapour) more than did those of $\beta$ elemene and caryophyllene, respectively (Table 2). However, the scores obtained for the three components were slightly different compared with the control. This might demonstrate that not only one component of this essential oil provided the sensory effects on cooked brown rice, but instead, the combination of the major components, minor components and other components took a part in the improvement. Accordingly, essential oils are natural, complex aromatic compounds, and their odours and flavours are obtained from the collaboration of many volatile components (Xiao et al. 2017a, b).

Linalool has a strong pleasant aroma because of the acyclic monoterpene, which is described as a floral, citrus and sweet odour (Asikin et al. 2018). It is extensively used as a fragrant ingredient in many cosmetic and cleaning products. Furthermore, it is commonly used as a fragrance and flavour agent in food products (Aprotosoaie et al. 2014). Therefore, linalool is the reasonable component which played the main role in improving the sensory qualities, especially the odour, flavour and taste, of cooked brown rice in this study. $\beta$-elemene is described as having a grassy and woody odour, and caryophyllene is described as having a chewing gum and woody odour (Asikin et al. 2018). Therefore, these compounds have a lesser effect on the odour of cooked brown rice when compared with linalool. In addition to the beneficial sensory qualities, these components have been proven to have many beneficial biological properties. Linalool has many properties, such as antimicrobial, sedative, anxiolytic, analgesic, anticonvulsant and anti-inflammatory effects (Aprotosoaie et al. 2014). $\beta$-elemene has been used as an anticancer drug (Zhao et al. 2007). Caryophyllene has been reported to have anticancer, anti-inflammatory, antioxidant and antimicrobial activities (Basha and Sankaranarayanan 2016). 
Table 2 The components presented in $M$. alba oil, brown rice grain samples and cooked brown rice samples

\begin{tabular}{|c|c|c|c|c|}
\hline \multirow[t]{2}{*}{ Component } & \multirow[t]{2}{*}{ R.T } & \multicolumn{3}{|l|}{ Peak area $(\%)$} \\
\hline & & $\begin{array}{l}\text { M. alba flower } \\
\text { oil }\end{array}$ & $\begin{array}{l}\text { Brown rice } \\
\text { grain }\end{array}$ & $\begin{array}{l}\text { Cooked brown } \\
\text { rice }\end{array}$ \\
\hline Methyl-2-butan-1-ol & 5.61 & 0.16 & - & - \\
\hline Methyl 2-methylbutyrate & 6.19 & 4.05 & 9.98 & - \\
\hline Ethyl 2-methylbutyrate & 7.25 & 0.36 & - & - \\
\hline Ethyl 3-methylbutanoate & 7.30 & 0.15 & - & - \\
\hline Methyl 2-methylcrotonate & 7.52 & 0.23 & - & - \\
\hline Methylethylacetic acid & 8.23 & 1.55 & 9.21 & - \\
\hline$\alpha$-Pinene & 8.71 & 0.24 & 0.11 & - \\
\hline (-)-camphene & 8.98 & 0.11 & - & - \\
\hline Hexanoic acid & 9.94 & 0.06 & - & - \\
\hline$\beta$-Pinene & 9.43 & 0.48 & 0.22 & - \\
\hline$\beta$-Myrcene & 9.52 & 0.12 & - & - \\
\hline o-Cymene & 10.13 & 0.07 & - & - \\
\hline 1,5-Cyclooctadiene, 1,5-dimethyl- & 10.21 & 0.19 & - & - \\
\hline$\beta$-cis-Ocimene & 10.27 & 2.94 & 1.61 & 2.14 \\
\hline 3-Carene & 10.45 & 2.84 & 1.42 & 2.36 \\
\hline$\gamma$-Terpinene & 10.66 & 0.07 & - & - \\
\hline Ethyl 2-(5-methyl-5-vinyltetrahydrofuran-2-yl) propan-2-yl carbonate & 10.88 & 0.26 & 0.16 & - \\
\hline Cyclohexene, 1-methyl-4-(1-methylethylidene)- & 11.12 & 0.19 & - & - \\
\hline Linalool & 11.46 & 43.47 & 52.07 & 11.32 \\
\hline Phenylethyl alcohol & 11.68 & 0.69 & - & - \\
\hline endo-Borneol & 12.41 & 0.18 & - & - \\
\hline Terpinen-4-ol & 12.54 & 0.20 & - & - \\
\hline$\alpha$-Terpineol & 12.72 & 1.29 & 1.10 & - \\
\hline Anisole, p-allyl- & 12.77 & 0.16 & 0.08 & - \\
\hline Nerol & 13.45 & 0.56 & 0.14 & - \\
\hline Linalool oxide acetate & 13.92 & 0.20 & 0.10 & - \\
\hline Safrole & 14.04 & 0.10 & - & - \\
\hline 1H-indole & 14.11 & 0.09 & - & - \\
\hline$\delta$-Elemene & 14.70 & 0.15 & 0.12 & - \\
\hline$\alpha$-Cubebene & 14.86 & 0.34 & 0.30 & - \\
\hline Eugenol & 14.89 & - & 0.12 & 5.66 \\
\hline Cycloisosativene & 15.19 & 0.09 & - & - \\
\hline Copaene & 15.27 & 1.40 & 0.92 & 3.83 \\
\hline$\beta$-Elemene & 15.48 & 8.03 & 9.76 & 34.38 \\
\hline cis- $\alpha$-Bergamotene & 15.76 & 0.21 & 0.34 & 1.43 \\
\hline$\alpha$-Santalene & 15.86 & 0.23 & - & - \\
\hline Caryophyllene & 16.01 & 6.80 & 4.90 & 19.58 \\
\hline Bicyclosesquiphellandrene & 16.06 & 0.16 & - & - \\
\hline$\alpha$-Guaiene & 16.11 & 0.16 & - & - \\
\hline (E)- $\beta$-Famesene & 16.17 & 0.20 & - & - \\
\hline Cadina-3,5-diene & 16.36 & 0.13 & - & - \\
\hline 1,4,7, -Cycloundecatriene, 1,5,9,9-tetramethyl-, Z, Z, Z- & 16.46 & 1.71 & 1.23 & 5.30 \\
\hline$\gamma$-Muurolene & 16.55 & 0.10 & - & - \\
\hline Methyl isoeugenol & 16.85 & 3.30 & - & - \\
\hline$\beta$-Selinene & 16.95 & 4.00 & 3.54 & 5.74 \\
\hline 1R,4R,7R,11R-1,3,4,7 Tetramethyltricyclo [5.3.1.0(4,11)] undec-2-ene & 17.05 & 2.25 & - & - \\
\hline
\end{tabular}


Table 2 continued

\begin{tabular}{|c|c|c|c|c|}
\hline \multirow[t]{2}{*}{ Component } & \multirow[t]{2}{*}{ R.T } & \multicolumn{3}{|l|}{ Peak area $(\%)$} \\
\hline & & $\begin{array}{l}\text { M. alba flower } \\
\text { oil }\end{array}$ & $\begin{array}{l}\text { Brown rice } \\
\text { grain }\end{array}$ & $\begin{array}{l}\text { Cooked brown } \\
\text { rice }\end{array}$ \\
\hline Eremophila-1(10),11-diene & 17.14 & 0.31 & - & - \\
\hline$\gamma$-Cadinene & 17.27 & 0.21 & - & - \\
\hline$\delta$-Cadinene & 17.38 & 3.30 & 1.37 & 5.96 \\
\hline Nerolidol & 17.79 & 0.74 & - & - \\
\hline$\alpha$-Calacorene & 18.01 & 0.08 & - & - \\
\hline Caryophyllene oxide & 18.45 & 0.70 & 0.26 & 0.94 \\
\hline Isoaromadendrene epoxide & 18.66 & 0.08 & - & - \\
\hline Isospathulenol & 18.78 & 0.09 & - & - \\
\hline Cubenol (1,10 di-epi) & 19.06 & 0.53 & - & - \\
\hline$\tau$-Muurolol & 19.27 & 0.93 & - & - \\
\hline$\alpha$-Cadinol & 19.48 & 0.27 & - & - \\
\hline Neointermedeol & 19.56 & 0.52 & - & - \\
\hline Spatulenol & 19.74 & 0.28 & - & - \\
\hline $\begin{array}{l}\text { 6-(1-Hydroxymethylvinyl)-4,8a-dimethyl-3,5,6,7,8,8a-hexahydro-1H- } \\
\text { naphthalen-2-one }\end{array}$ & 19.94 & 0.09 & - & - \\
\hline (1R,7S, E)-7-Isopropyl-4,10-dimethylenecyclodec-5-enol & 21.05 & 0.09 & - & - \\
\hline $\begin{array}{l}\text { Bicyclo[4.4.0]dec-5-ene, 1,5-dimethyl-3-hydroxy-8-(1-methylene-2- } \\
\text { hydroxyethyl-1)- }\end{array}$ & 21.36 & 0.09 & - & - \\
\hline 9-Cycloheptadecen-1-one, (Z)- & 22.78 & 0.24 & - & - \\
\hline Linoleic acid ethyl ester & 22.90 & 0.25 & - & - \\
\hline Nonadecane & 23.19 & 0.10 & - & - \\
\hline Hexadecanoic acid, methyl ester & 23.65 & 0.12 & 0.16 & 0.62 \\
\hline Hexadecanoic acid, ethyl ester & 24.81 & - & 0.77 & 0.74 \\
\hline 9,12-Octadecadienoic acid (Z,Z)-, methyl ester & 26.59 & 0.22 & - & - \\
\hline 9,12,15-Octadecatrienoic acid, methyl ester, (Z,Z,Z)- & 26.70 & 0.11 & - & - \\
\hline Total & & 99.62 & 100 & 100 \\
\hline
\end{tabular}

\section{Effect of M. alba oil vapour on the physical and chemical properties of brown rice}

The physical and chemical properties of brown rice treated and untreated with $M$. alba oil vapour are shown in Table 3. Results indicated that there were optimistic effects of $M$. alba oil vapour on the physical and chemical properties of brown rice. Treatment of brown rice with $M$. alba oil vapour could cause a significant reduction in the cooking time and the hardness of cooked brown rice, and a small change on the colour of cooked brown rice $\left(\Delta \mathrm{E}^{*}=\right.$ $2.54 \pm 0.63)$. Furthermore, it could increase the total phenolic content in brown rice. Moreover, the proximate composition analysis revealed that there were no significant negative effects of $M$. alba oil vapour on the quantity of the nutritional compositions in the brown rice.
The M. alba oil components which were absorbed in the brown rice according to the results in "Determination of a key component of $M$. alba oil vapour in sensory effects" section (Table 2), might be responsible for a decrease in cooking time and hardness of the cooked rice. In detail, this could be explained by the ability of the absorbed $M$. alba oil components to damage the rice bran layer of brown rice, thereby promoting the water uptake into the starch granule of brown rice and results into reduction in cooking time and hardness of cooked rice. In addition, the increase in the phenolic content in brown rice may be due to the accumulation of M. alba oil components in the brown rice since the M. alba oil contains several phenolic compounds. 
Table 3 The physical and chemical properties of brown rice treated and untreated with M. alba oil vapour

\begin{tabular}{|c|c|c|}
\hline \multirow[t]{2}{*}{ Quality factors } & \multicolumn{2}{|c|}{ Brown rice samples } \\
\hline & Control & Treatment with $M$. alba vapour $(600 \mu \mathrm{L} / \mathrm{L}$ air $)$ \\
\hline Cooking time (min) & $27.57 \pm 0.29^{\mathrm{a}}$ & $25.08 \pm 0.50^{\mathrm{b}}$ \\
\hline \multicolumn{3}{|l|}{ Colour } \\
\hline $\mathrm{L}^{*}$ & $65.97 \pm 0.55^{\mathrm{a}}$ & $63.65 \pm 0.21^{\mathrm{b}}$ \\
\hline$a^{*}$ & $3.64 \pm 0.11^{\mathrm{a}}$ & $3.81 \pm 0.16^{\mathrm{a}}$ \\
\hline $\mathrm{b}^{*}$ & $21.72 \pm 0.15^{\mathrm{a}}$ & $22.47 \pm 0.15^{\mathrm{a}}$ \\
\hline$\Delta \mathrm{E}^{*}$ & & $2.54 \pm 0.63$ \\
\hline \multicolumn{3}{|l|}{ Texture analysis } \\
\hline Hardness $(\mathrm{N})$ & $292.24 \pm 12.90^{\mathrm{a}}$ & $171.21 \pm 5.63^{\mathrm{b}}$ \\
\hline Springiness $(\mathrm{mm})$ & $4.64 \pm 0.04^{\mathrm{a}}$ & $4.54 \pm 0.13^{\mathrm{a}}$ \\
\hline Cohesiveness & $0.18 \pm 0.07^{\mathrm{a}}$ & $0.20 \pm 0.07^{\mathrm{a}}$ \\
\hline Adhesiveness (N) & $4.69 \pm 2.67^{\mathrm{a}}$ & $3.81 \pm 1.91^{\mathrm{b}}$ \\
\hline Gumminess (N) & $52.25 \pm 15.94^{\mathrm{a}}$ & $34.32 \pm 12.97^{\mathrm{b}}$ \\
\hline \multicolumn{3}{|l|}{ Proximate composition $(\% \mathrm{wt})$} \\
\hline Moisture (\%) & $15.33 \pm 0.05^{\mathrm{a}}$ & $15.64 \pm 0.05^{\mathrm{a}}$ \\
\hline Total protein $(\%$ & $7.25 \pm 0.05^{\mathrm{a}}$ & $7.31 \pm 0.04^{\mathrm{a}}$ \\
\hline Lipids content $(\%)$ & $2.36 \pm 0.05^{\mathrm{a}}$ & $2.28 \pm 0.04^{\mathrm{a}}$ \\
\hline $\operatorname{Ash}(\%)$ & $1.17 \pm 0.04^{\mathrm{a}}$ & $1.18 \pm 0.01^{\mathrm{a}}$ \\
\hline Crude fiber $(\%)$ & $0.40 \pm 0.03^{\mathrm{a}}$ & $0.35 \pm 0.01^{\mathrm{a}}$ \\
\hline Total carbohydrate $(\%)$ & $73.49 \pm 1.51^{\mathrm{a}}$ & $73.24 \pm 1.49^{\mathrm{a}}$ \\
\hline Total phenolic content (mg gallic acid/g) & $0.50 \pm 0.01^{\mathrm{b}}$ & $0.82 \pm 0.01^{\mathrm{a}}$ \\
\hline
\end{tabular}

${ }^{\mathrm{a}, \mathrm{b}}$ Different superscripts are significantly different $(p<0.05)$

\section{Effect of cooked brown rice containing $M$. alba oil vapour on human brain activity}

The results of the effect of cooked brown rice on human brain activity are shown in Fig. 2 and Table 4. The results indicated that consumption of cooked brown rice both treated with $M$. alba oil vapour and untreated could increase human brain waves in the alpha band $(8-13 \mathrm{~Hz})$ and the beta band $(13-30 \mathrm{~Hz})$. The alpha band started to increase during smelling the odour of the cooked brown rice and strongly increased after participants chewed and swallowed the samples. The comparison between untreated cooked brown rice samples and those treated with $M$. alba oil vapour showed that the consumption of treated cooked brown rice could increase the power of the slow alpha waves $(9 \mathrm{~Hz})$ more than could the untreated cooked brown rice $(p<0.05)$. The power of the slow alpha waves $(9 \mathrm{~Hz})$ noticeably increased when the participants began to smell the odour of treated cooked brown rice samples and continued until $5 \mathrm{~min}$ after swallowing the samples. In addition, the consumption of treated cooked brown rice could increase the power of low beta waves $(14 \mathrm{~Hz})$ and high beta waves $(25 \mathrm{~Hz})$ after swallowing the sample more than could the consumption of the untreated cooked brown rice sample $(p<0.05)$.

These results demonstrated that the odour and flavour of $M$. alba oil in cooked brown rice could stimulate the human brain to provide increased alpha and beta waves. As noted, this stimulation was evident during smelling the odour of the rice and after chewing and swallowing. Generally, alpha waves are related to semantic information processing and to good cognitive performance (Klimesch 1999), whereas beta waves play an important role in attention or higher cognitive functions (Sauseng et al. 2009). Moreover, the increase of the slow beta wave band $(8-11 \mathrm{~Hz})$ correlates with a relaxed state. The low beta wave band $(13-15 \mathrm{~Hz})$ and high beta wave band $(20-30 \mathrm{~Hz})$ are correlated with musing and complex thoughts, respectively. A high ratio of alpha to high beta indicates a very calm and relaxed state (Subha et al. 2010). Therefore, increased alpha and beta wave power could indicate anti-stress effects and a relaxed mood.

This finding is similar to the effects of other foods on human brain activity. A study by Labbe et al. (2011) reported the effect of refreshing perception from a refreshing drink on consumers' emotional responses. The EEG wave forms obtained immediately before and $15 \mathrm{~min}$ 

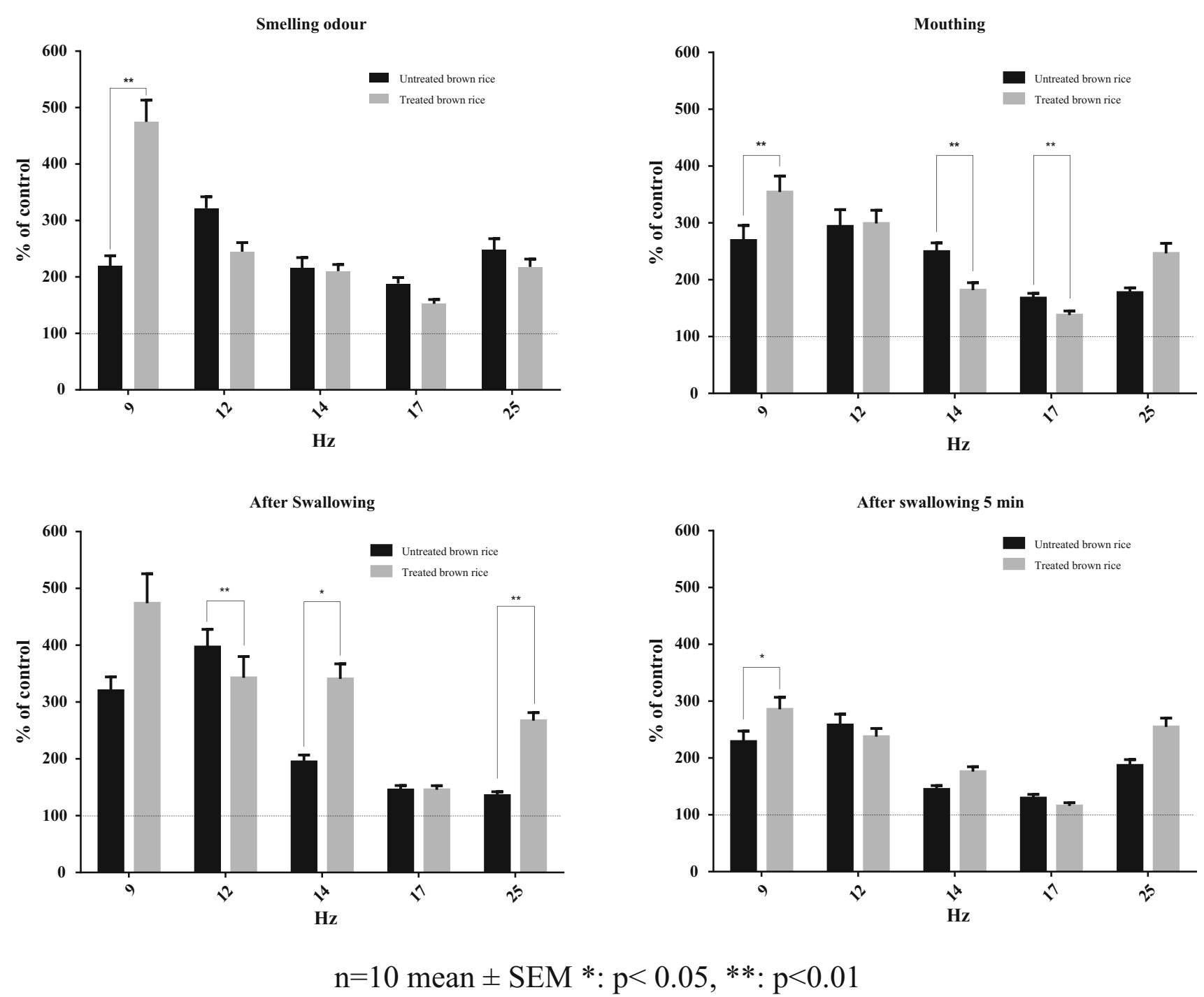

Fig. 2 Spectral analysis of human brain waves in the alpha and beta wave ranges from cooked brown rice consumption. The dashed line was adjusted to $100 \%$ from eye-close wave power without stimulus (baseline) prior to testing conditions

after drinking the refreshing drink were considered to improve the effect of refreshing perception on mental energy in terms of cortical activation and cognitive performance. It was demonstrated that drinking the refreshing drink could increase the alpha and beta wave activity in the brain. In addition, a study by Murao et al. (2013) showed that smelling green tea, especially shaded white tea, could also increase the alpha and beta brain wave activity in the frontal and occipital regions.

Moreover, the results of this study illustrated that the measurement of brain activity by EEG techniques can provide useful data to support the understanding of consumer responses to cooked brown rice treated with $M$. alba oil vapour in terms of brain function. This technique is suggested as an interesting technique that can be applied in the consumer and sensory research of food products.

\section{Conclusion}

M. alba oil vapour provided effective antifungal activity against $A$. flavus $(\geq 450 \mu \mathrm{L} / \mathrm{L})$ on MEA and brown rice. Furthermore, consumers accepted cooked brown rice treated with $M$. alba oil vapour at concentrations $300-600 \mu \mathrm{L} / \mathrm{L}$ (optimal at $600 \mu \mathrm{L} / \mathrm{L}$ ), and a rejection threshold of $2052 \mu \mathrm{L} / \mathrm{L}$ was determined. EEG results suggested that the consumption of cooked brown rice treated with $M$. alba oil vapour at $600 \mu \mathrm{L} / \mathrm{L}$ could increase the power of alpha and beta waves in the human brain, promoting anti-stress effects and a relaxed mood. Therefore, $M$. alba oil vapour demonstrated good potential to enhance consumer preference for cooked brown rice and control significant growth of A. flavus in brown rice and 
Table 4 Power of slow-fast alpha and low-mid-high beta waves during and after consumption of cooked brown rice

\begin{tabular}{|c|c|c|c|c|c|c|}
\hline \multirow[t]{3}{*}{ Step } & \multirow[t]{3}{*}{ Frequency $(\mathrm{Hz})$} & \multicolumn{4}{|c|}{ Power $\left(\mu \mathrm{V}^{2}\right)$} & \multirow[t]{3}{*}{$P$ value } \\
\hline & & \multicolumn{2}{|c|}{ Untreated brown rice } & \multicolumn{2}{|c|}{ Treated brown rice } & \\
\hline & & Mean & SEM & Mean & SEM & \\
\hline \multirow[t]{5}{*}{ Smelling odour } & 9 & 0.0903 & 0.0072 & 0.1521 & 0.0124 & $<0.0001$ \\
\hline & 12 & 0.1037 & 0.0066 & 0.0735 & 0.0048 & 0.4457 \\
\hline & 14 & 0.0237 & 0.0020 & 0.0252 & 0.0014 & 0.5059 \\
\hline & 17 & 0.0245 & 0.0014 & 0.0198 & 0.0010 & 0.9416 \\
\hline & 25 & 0.0174 & 0.0014 & 0.0109 & 0.0007 & 0.8807 \\
\hline \multirow[t]{5}{*}{ Mouthing } & 9 & 0.1104 & 0.0109 & 0.1135 & 0.0090 & $<0.0001$ \\
\hline & 12 & 0.0954 & 0.0095 & 0.0894 & 0.0070 & 0.4817 \\
\hline & 14 & 0.0274 & 0.0017 & 0.0218 & 0.0016 & $<0.0001$ \\
\hline & 17 & 0.0218 & 0.0011 & 0.0179 & 0.0010 & $<0.0001$ \\
\hline & 25 & 0.0124 & 0.0006 & 0.0123 & 0.0009 & 0.0803 \\
\hline \multirow[t]{5}{*}{ After swallowing } & 9 & 0.1314 & 0.0100 & 0.1519 & 0.0166 & 0.2189 \\
\hline & 12 & 0.1288 & 0.0102 & 0.1029 & 0.0113 & 0.0003 \\
\hline & 14 & 0.0214 & 0.0013 & 0.0409 & 0.0032 & 0.0224 \\
\hline & 17 & 0.0188 & 0.0010 & 0.0189 & 0.0009 & 0.7411 \\
\hline & 25 & 0.0095 & 0.0005 & 0.0134 & 0.0007 & $<0.0001$ \\
\hline \multirow[t]{5}{*}{ After swallowing $5 \mathrm{~min}$} & 9 & 0.0916 & 0.0076 & 0.0940 & 0.0068 & 0.0347 \\
\hline & 12 & 0.0837 & 0.0061 & 0.0713 & 0.0043 & 0.1613 \\
\hline & 14 & 0.0159 & 0.0007 & 0.0211 & 0.0010 & 0.1195 \\
\hline & 17 & 0.0169 & 0.0008 & 0.0150 & 0.0007 & 0.1909 \\
\hline & 25 & 0.0131 & 0.0007 & 0.0127 & 0.0008 & 0.1028 \\
\hline
\end{tabular}

may prove useful in the improvement of brown rice quality.

Acknowledgements This study was supported by the Thailand Research Fund (TRF) and was partially supported by the Institute of Research and Innovation, Walailak University, Thailand (Contract Number WU62258). EEG tracings were supported by Research Institute of Health Sciences, Walailak University.

\section{References}

Aprotosoaie AC, Hăncianu M, Costache II, Miron A (2014) Linalool: a review on a key odorant molecule with valuable biological properties. Flavour Fragr J 29:193-219

Asaruddin MR, Honda G, Tsubouchi A, Nakajima-Shimada J, Aoki T, Kiuchi F (2003) Trypanocidal constituents from Michelia alba. Nat Med 57:61-63

Asikin Y, Kawahira S, Goki M, Hirose N, Kyoda S, Wada K (2018) Extended aroma extract dilution analysis profile of Shiikuwasha (Citrus depressa Hayata) pulp essential oil. J Food Drug Anal 26:268-276

Association of Official Analytical Chemists (2019) Official methods of analysis, 21st edn. Association of Official Analytical Chemists, Washington

Basha RH, Sankaranarayanan C (2016) $\beta$-Caryophyllene, a natural sesquiterpene lactone attenuates hyperglycemia mediated oxidative and inflammatory stress in experimental diabetic rats. Chem Biol 245:50-58

Della Lucia SM, Rodrigues Minim VP, Osório Silva CH, Minim LA, De Aguiar CP (2014) Use of relative risk test to evaluate the influence of the brand on beer acceptability. Semin Cienc Agrar 35:267-276

Desmet PMA, Hekkert P (2009) Special issue editorial: design \& emotion. Int J Des 3:1-6

Espina L, García-Gonzalo D, Pagán R (2014) Impact of essential oils on the taste acceptance of tomato juice, vegetable soup, or poultry burgers. J Food Sci 79:1575-1583

Galanakis CM (2012) Recovery of high added-value components from food wastes: conventional, emerging technologies and commercialized applications. Trends Food Sci Technol 26:68-87

Galanakis CM (2013) Emerging technologies for the production of nutraceuticals from agricultural by-products: a viewpoint of opportunities and challenges. Food Bioprod Process 91:575-579

Galanakis CM (2015) Separation of functional macromolecules and micromolecules: from ultrafiltration to the border of nanofiltration. Trends Food Sci Technol 42:44-63

Galanakis CM (2020) The food systems in the era of the coronavirus (COVID-19) pandemic crisis. Foods 9(523):1-10

Hongratanaworakit T, Buchbauer G (2004) Evaluation of the harmonizing effect of ylang-ylang oil on humans after inhalation. Planta Med 70:632-636

Kalpanadevi C, Singh V, Subramanian R (2018) Influence of milling on the nutritional composition of bran from different rice varieties. J Food Sci Technol 55:2259-2269

Kaneda H, Goto N, Kobayakawa T, Takashio M, Saito S (2004) Measurement of human brain activity evoked by stimulation of beer bitterness using magnetoencephalography. J Food Sci 69:156-160

Kim IH, Lee H, Kim JE, Song KB, Lee YS, Chung DS, Min SC (2013) Plum coatings of lemongrass oil-incorporating carnauba wax-based nanoemulsion. J Food Sci 78:1551-1559 
King SC, Meiselman HL (2010) Development of a method to measure consumer emotions associated with foods. Food Qual Perfer 21:168-177

Klimesch W (1999) EEG alpha and theta oscillations reflect cognitive and memory performance: a review and analysis. Brain Res Rev 29:169-195

Labbe D, Martin N, Le Coutre J, Hudry J (2011) Impact of refreshing perception on mood, cognitive performance and brain oscillations: an exploratory study. Food Qual Perfer 22:92-100

Lagast S, Gellynck X, Schouteten JJ, De Herdt V, De Steur H (2017) Consumers' emotions elicited by food: a systematic review of explicit and implicit methods. Trends Food Sci Technol 69:172-189

Lee J, Jung E, Park J, Jung K, Lee S, Hong S et al (2005) Antiinflammatory effects of magnolol and honokiol are mediated through inhibition of the downstream pathway of MEKK-1 in NF- $\kappa B$ activation signaling. Planta Med 71:338-343

Lima Filho T, Minim VPR, Dos Santos Navarro RDC, Della Lucia SM, Minim LA (2015) Methodology for determination of two new sensory thresholds: compromised acceptance threshold and rejection threshold. Food Res Int 76:561-566

Meilgaard MC, Carr BT, Civille GV (1999) Sensory evaluation. CRC Press, Boca Raton

Murao S, Yoto A, Yokogoshi H (2013) Effect of smelling green tea on mental status and EEG activity. Int J Affect Eng 12:37-43

Rout PK, Naik SN, Rao YR (2006) Composition of the concrete, absolute, headspace and essential oil of the flowers of Michelia champaca Linn. Flavour Frag J 21:906-911

Sapna I, Kamaljit M, Priya R (2019) Milling and thermal treatment induced changes on phenolic components and antioxidant activities of pigmented rice flours. J Food Sci Technol $56: 273-280$

Sauseng P, Klimesch W, Gerloff C, Hummel FC (2009) Spontaneous locally restricted EEG alpha activity determines cortical excitability in the motor cortex. Neuropsychologia 47:284-288

Songsamoe S, Matan N, Matan N (2016) Effect of UV-C radiation and vapor released from a water hyacinth root absorbent containing bergamot oil to control mold on storage of brown rice. J Food Sci Technol 53:1445-1453

Songsamoe S, Matan N, Matan N (2017) Antifungal activity of Michelia alba oil in the vapor phase and the synergistic effect of major essential oil components against Aspergillus flavus on brown rice. Food Control 77:150-157

Subha DP, Joseph PK, Acharya R, Lim CM (2010) EEG signal analysis: a survey. J Med Syst 34:195-212

Suhem K, Matan N, Matan N, Danworaphong S, Aewsiri T (2015) Improvement of the antifungal activity of Litsea cubeba vapor by using a helium-neon (He-Ne) laser against Aspergillus flavus on brown rice snack bars. Int J Food Microbiol 215:157-160

Suppakul P, Sonneveld K, Bigger SW, Miltz J (2011) Diffusion of linalool and methylchavicol from polyethylene-based antimicrobial packaging films. LWT Food Sci Technol 44:1888-1893

Tyagi AK, Malik A, Gottardi D, Guerzoni ME (2012) Essential oil vapour and negative air ions: a novel tool for food preservation. Trends Food Sci Technol 26:99-113

Vollmuth TA, Heck JD, Ratajczak HV, Thomas PT (1989) Immunotoxicity assessment of flavoring ingredients using a rapid and economical screen. Toxicologist 9:206

Worch T, Sinesio F, Moneta E, Abbà S, Dreyfuss L, McEwan JA, Porcherot-Lassallette C (2020) Influence of different test conditions on the emotional responses elicited by beers. Food Qual Perfer 83:103895

Xiao Z, Chen J, Niu Y, Chen F (2017a) Characterization of the key odorants of fennel essential oils of different regions using GCMS and GC-O combined with partial least squares regression. J Chromatogr B1063:226-234

Xiao Z, Li Q, Niu Y, Zhou X, Liu J, Xu Y, Xu Z (2017b) Odor-active compounds of different lavender essential oils and their correlation with sensory attributes. Ind Crops Prod 108:748-755

Zeng WC, Zhu RX, Jia LR, Gao H, Zheng Y, Sun Q (2011) Chemical composition, antimicrobial and antioxidant activities of essential oil from Gnaphlium affine. Food Chem Toxicol 49:1322-1328

Zhao J, Li QQ, Zou B, Wang G, Li X, Kim JE et al (2007) In vitro combination characterization of the new anticancer plant drug $\beta$ elemene with taxanes against human lung carcinoma. Int J Oncol $31: 241-252$

Publisher's Note Springer Nature remains neutral with regard to jurisdictional claims in published maps and institutional affiliations. 